\title{
POLÍTICA E FORMAÇÃO CONTINUADA DE EDUCADORES: UM OLHAR PARA A DOCÊNCIA UNIVERSITÁRIA A PARTIR DA DECOLONIALIDADE DA EDUCAÇÃO
}

\author{
POLICIES AND CONTINUING TEACHEREDUCATION: A LOOK AT \\ UNIVERSITY TEACHING FROM THE DECOLONIALITY OF \\ EDUCATION
}

\author{
Júlia Figueredo Benzaquen \\ Pós-doutorado em Educação Contemporânea, \\ Centro Acadêmico do Agreste da Universidade Federal de Pernambuco - CAA, UFPE \\ Caruaru, Pernambuco - Brasil \\ julia.benzaquen@ufrpe.br \\ Bruna Tarcilia Ferraz \\ Doutorado em Educação, Universidade Federal de Pernambuco - UFPE \\ Recife, Pernambuco - Brasil \\ btf1@hotmail.com
}

\begin{abstract}
Resumo:O artigo objetiva analisar a percepção de docentes universitários sobre práticas de formação continuada de professores da educação básica. Refletindo a respeito das suas ações enquanto formadores nesses cursos, os docentes do ensino superior revelam que os cursos de formação de professores da educação básica são espaços privilegiados para se pensar formas de decolonizar o ensino. Realizamos entrevistas com coordenadores(as) de curso e formadores(as) universitários(as) que atuaram em cursos de especialização ofertados pela Rede Nacional de Formação Inicial e Continuada de Profissionais da Educação Básica (RENAFORM), em 2014, na Universidade Federal Rural de Pernambuco (UFRPE), no Brasil. As políticas e propostas dos cursos eram de uma formação decolonial, no sentido que visavam à valorização de outros saberes, bem como dos sujeitos do campo, indígenas, negros, crianças, etc. As conclusões são que há limites no processo de implementação da referida política e fica claro que não basta um currículo decolonial, é preciso também uma prática. A universidade se enriquece com a possibilidade de compreender as demandas do chão da escola, bem como os professores do ensino básico são estimulados a prosseguirem no aprimoramento da sua formação, a nível de pós-graduação. Essa troca favorece a decolonialidade, constituindo-se em processo de construção que prevê redefinições, tanto na configuração da profissionalidade docente como na produção do conhecimento nos cursos de formação continuada.
\end{abstract}

Palavras-chave: Decolonialidade da educação. Docência universitária. Formação continuada.

\begin{abstract}
The article aims to analyze the perception of university professors about continuing education practices of basic education teachers. Reflecting on their actions as trainers in these courses, professors reveal that basic education teacher training courses are privileged spaces for thinking about ways to decolonize teaching. We conducted interviews with course coordinators and university trainers who worked in specialization courses offered by the National Network of Initial and Continuing Education of School Professionals (RENAFORM), in 2014, at the Federal Rural University of Pernambuco (UFRPE) in Brazil. The courses' policies and proposals were of a decolonial education, in the sense that they aimed at valuin $g$ other knowledges, as well as other subjects such as rural, indigenous and black people, children, etc. The conclusions are that there are limits to the process of implementing this policy and it is clear that a decolonial curriculum is not enough, a practice is also necessary. The university is enriched by the possibility of understanding the demands of the school, while school teachers are encouraged to continue to improve their postgraduate education. This exchange favors decoloniality, which is a construction process that foresees redefinitions both in the configuration of teaching professionalism and in the production of knowledge in continuing education courses.
\end{abstract}

Keywords: Decoloniality of education. University teaching. Continuing education.

Para citar - (ABNT NBR 6023:2018)

BENZAQUEN, Júlia Figueredo; FERRAZ, Bruna Tarcilia. Política e formação continuada de educadores: um olhar para a docência universitária a partir da decolonialidade da educação. Eccos - Revista Cientifica, São Paulo, n. 54, p. 1-15, e17351, jul./set. 2020. Disponível em: https://doi.org/10.5585/eccos.n54.17351. 


\section{Introdução}

O pensamento decolonial constitui-se em desafio para o campo da educação, independentemente do nível de ensino. No tocante à presente pesquisa, o desafio constitui-se em perceber limites e possibilidades de construção do saber e da prática decoloniais na configuração da profissionalidade docente universitária no contexto das políticas de formação continuada para a educação básica. Buscamos neste artigo evidenciar como é realizada essa dinâmica, considerando as trocas formativas ocorridas entre docentes universitários e docentes da educação básica.

A partir daí, passamos a refletir sobre algumas questões: qual é a relação entre as políticas de formação continuada e a profissionalidade docente universitária? Os saberes e o cotidiano dos docentes na educação básica são considerados no planejamento da formação continuada? De que forma a assimetria de poder entre docente universitário e professores da educação básica se constitui uma forma de colonialidade? Como estabelecer processos dialógicos formativos decoloniais entre os dois sujeitos (professores universitários e docentes do ensino básico)? Como decolonizar práticas e saberes das políticas de formação continuada?

Para responder a essas inquietações, o texto se estrutura da seguinte forma: Na próxima seção, fazemos uma reflexão teórica sobre as relações entre o pensamento decolonial e a educação, uma teoria que nos serve de base para a posterior análise dos dados. Seguimos, então, para uma seção dedicada à reflexão teórica que contextualiza os dados, trazendo elementos para pensarmos a docência universitária e as práticas de formação continuada. Situamos a seguir os passos metodológicos, a forma pela qual acessamos a realidade para depois apresentarmos o empírico, primeiramente caracterizando os sujeitos da pesquisa e depois nos debruçando sobre a relação entre a política de formação continuada e a reflexão sobre a profissionalidade docente universitária. Por fim, apontamos os limites e as possibilidades da política.

\section{Pensamento decolonial e educação: alguns apontamentos}

$\mathrm{Na}$ atualidade, a palavra educação é, muitas vezes, apropriada por um projeto colonial de formação do humano que se restringe a reproduzir a colonialidade do saber, do ser e do poder. O termo colonialidade, assim cunhado por Quijano (2002), enfatiza a continuidade entre o tempo e os espaços coloniais e o tempo e espaços pós-coloniais. O conceito de colonialidade evidencia que as relações coloniais não se limitam ao domínio econômico-político e jurídicoadministrativo dos centros sob as periferias, mas também a uma dimensão epistêmica, cultural 
e racial desse domínio. É dessa maneira que as sociedades "periféricas" ou "ex-colônias", bem como as reivindicações e experiências vivenciadas por minorias sociais, continuam sendo tratadas a partir de suas relações de funcionalidade, semelhanças ou divergências com aquilo que se definiu como "centro" (COSTA, 2013).

A ideia de colonialidade supõe a imposição de um sistema de classificação hierárquica de conhecimentos, espaços e pessoas. Quijano (2002) fala em colonialidade do poder, que abrangeria os três âmbitos: saberes, práticas e sujeitos. De forma analítica, é possível dizer que a colonialidade opera em três níveis: a colonialidade do poder ou a colonialidade da economia, da política e das instituições; a colonialidade do saber, que se encontra nos níveis epistêmico, filosófico, científico e na relação língua-conhecimento; e a colonialidade do ser, que opera na subjetividade, no controle da sexualidade, nos papéis atribuídos.

Existe um debate sobre a diferença entre colonialismo, pós-colonialismo, colonialidade, descolonialidade e decolonialidade. Enquanto o colonialismo se restringe ao período histórico de administração econômica e política de uma metrópole sob uma colônia, a colonialidade implica a sofisticação do colonialismo ao exercer o domínio e a opressão, mesmo sem uma estrutura político-administrativa. A colonialidade se refere a processos de opressão que subjugam o outro a partir de uma heterarquia (KONTOPOULOS, 1993), ou seja, de hierarquias heterogêneas, complexas e enredadas que não são passíveis de explicação através do paradigma moderno.

A perspectiva teórico-metodológica pós-colonial surge a partir de processos de libertação recentes de países africanos e asiáticos. Na academia, surge na década de 1980 muito relacionada a autores das Letras. Essa vertente se inspira e dialoga com diferentes correntes teóricas tais quais o marxismo, o feminismo e o pós-estruturalismo e adquire características próprias a partir do lócus de enunciação dos seus autores. Na América Latina, a teoria de sistema-mundo (WALLERSTEIN, 1974), as teorias da dependência (Quijano [2002] foi um dos sociólogos que se vinculou a essa perspectiva), a filosofia da libertação (DUSSEL, 1977), bem como a pedagogia da libertação (FREIRE, 2002) são influências constituintes.

O grupo de autores da América Latina que tratam dessa temática e que ficaram conhecidos como grupo modernidade/colonialidade, constituído por nomes tais quais Quijano (2002), Mignolo (2000), Dussel (1977) e Grosfoguel (2006), trava um debate sobre o que os diferencia da corrente pós-colonial e o fazem adotar o termo descolonial. A centralidade da América Latina para entender o sistema-mundo moderno colonial, a crítica a estudos meramente culturais e a necessidade de considerar o capitalismo são alguns dos elementos utilizados para estabelecer essa distinção. 
A diferença entre descolonial e decolonial é explicada por Walsh (2009), que prefere suprimir o "s" para explicitar que a intenção não é desfazer o colonial ou viver um momento após a colonização (pós-colonial), mas sim desestabilizar e questionar a ordem vigente. $\mathrm{O}$ decolonial não retira o "s" por advir de uma tradução do inglês de decoloniality mas pela intenção de ser um posicionamento político, bem como teórico-metodológico.

Paulo Freire (2002), uma das inspirações dos teóricos decoloniais latino-americanos, ajuda a pensar o decolonial da educação, apesar de nunca ter usado o termo colonialidade, pois a maioria de seus escritos são anteriores a essa perspectiva teórica-metodológica ganhar notoriedade. Uma forma de a educação reproduzir a colonialidade é através do que Freire (ibidem) define como educação bancária. 'Eis aí a concepção 'bancária' da educação, em que a única margem de ação que se oferece aos educandos é a de receberem depósitos, guardá-los e arquivá-los" (ibidem, p. 58). O educando entende a educação bancária como um recipiente vazio que deve ser preenchido pelos "únicos saberes verdadeiros", que são aqueles do professor. Nessa concepção de educação, não há espaço para a criatividade, para a transformação social, para o saber decolonizado.

Santos (2009) afirma que grande parte das instituições escolares se baseiam em um modelo que visa a converter todos os problemas sociais e políticos em problemas técnicos e resolvê-los de modo científico, isto é, eficazmente com total neutralidade social e política. A permanência desse modelo de aplicação técnica da ciência nas escolas só é compreensível por inércia e/ou por má-fé: "pela inércia da cultura oficial e das burocracias educativas, pela má-fé da institucionalidade capitalista que utiliza o modelo de aplicação técnica para ocultar o caráter político e social da desordem que instaura" (SANTOS, 2009, p. 22).

Com esse tipo de escola, a educação deixa de ser instrumento de emancipação humana e passa a ser mecanismo de perpetuação e reprodução do sistema colonial moderno. A partir de uma perspectiva decolonial, a educação deve ser entendida como sinônimo de formação humana. Ou seja, ser apropriada por um projeto formativo do humano como produção histórica das virtualidades positivas do ser humano, na complexidade ontológica do desenvolvimento material e espiritual do homem como ser social.

O conceito de educação se diminui quando é pensada apenas como transmissão dos saberes e habilidades demandados pela produção e pelo mercado ou para formação de uma cidadania estadocêntrica. Na contramão dos dispositivos educacionais da modernidade, destaca-se a importância de desenvolver a noção de educação como projeto e ação coletivos, conhecendo e valorizando a memória e a experiência humanas. É preciso pensar a formação do 
ser humano como foco da teoria pedagógica e de toda prática educativa e, assim, ampliar o conceito de educação de uma forma que considere o peso formativo dos processos sociais.

\section{Profissionalidade docente e práticas de formação continuada}

A universidade é um espaço reconhecido, segundo Ramos (2010, p. 20), como "lócus privilegiado de reflexão, cultivo e transmissão do saber acumulado". Haja vista esse fato, diversas políticas voltadas para a formação de professores, que se sustentam na viabilização e aprimoramentos dos saberes legitimados, são conferidas à universidade. Nesse contexto, a Rede Nacional de Formação dos Profissionais da Educação Básica (RENAFORM), que foi instituída pelo Ministério da Educação (MEC), por meio da Portaria n. 1.328/11, passa a ser executada com o objetivo de promover formação, no bojo do debate das políticas públicas.

A formação continuada constitui-se numa demanda social, uma vez que, para alcançarmos qualidade na educação, precisamos considerar a qualificação dos profissionais que atuam no campo. Em meio a esse cenário, e procurando atender às demandas legais, a própria Lei de Diretrizes e Bases da Educação Nacional (LDBEN, Lei n. 9.394/96) veio provocar especialmente os poderes públicos quanto a essa formação.

Faz-se necessário pensar a formação continuada, considerando as especificidades da formação inicial. Por isso, analisando efetivas políticas públicas de formação continuada dos professores da educação básica, Gatti (2008) destaca que, pelos déficits da qualidade das formações iniciais dos docentes, "muitas das iniciativas públicas de formação continuada no setor educacional adquiriram, então, a feição de programas compensatórios e não propriamente de atualização e aperfeiçoamento [...]" (p. 58).

Gatti (ibidem) defende o caráter público dessa política de formação continuada, evidenciando a importância do planejamento e das ofertas de esses cursos serem feitos por parte das Instituições de Educação Superior (IES) e Institutos Federais de Educação, Ciência e Tecnologia (IF), como foi concebida na Portaria ME n. 1.328, de 23 de setembro de 2011.

Nesse sentido, é importante destacar elementos da construção da profissionalidade docente universitária. Segundo Roldão (2005), ela exige: o reconhecimento social da especificidade da função associada à atividade docente; o saber específico indispensável ao desenvolvimento da atividade e sua natureza; o controle sobre a atividade e a autonomia do seu exercício; e a pertença a um corpo coletivo que partilha, regula e defende a atividade (p. 109).

Essas características trazidas por Roldão (ibidem), no âmbito das políticas de formação continuada, influenciam a configuração da docência universitária, possibilitando a reflexão 
sobre a construção dos saberes, principalmente em um contexto destacado por Zabalza (2004), que prevê a configuração da docência universitária a partir de três dimensões: a profissional, a administrativa e a pessoal.

Percebemos, então, que a profissionalidade constitui-se em conceito complexo, dono das mais diversas explicações que perpassam por questões contextuais, temporais, práticas, assim como ligadas à identidade profissional docente (RAMOS, 2010). Morgado (2005) destaca elementos fundamentais da profissionalidade, como as competências profissionais, a cultura profissional e a identidade profissional. Assim, percebemos que tanto fatores internos como externos influenciam a configuração da profissionalidade docente.

Essa profissionalidade docente universitária pode ser decolonial, caso consiga ser exercida a partir do que Freire (1996) denomina de uma aprendizagem em comunhão, na qual todos os sujeitos envolvidos no processo estão aprendendo, inclusive o professor universitário. Segundo o autor, nas condições de verdadeira aprendizagem, os educandos vão se transformando em sujeitos da construção e da reconstrução do saber ensinando, ao lado do educador, igualmente sujeito do processo (ibidem, p. 14).

\section{Situando passos metodológicos}

A metodologia constitui-se em fase importante da pesquisa social, pois prevê a descrição da fase de exploração de campo, as etapas do trabalho de campo e os procedimentos para análise (DESLANDES, 2008). Minayo (2010) destaca que a metodologia em pesquisa científica vai além de um conjunto de técnicas, e que podemos encarar como um conjunto de concepções teóricas de abordagens, favorecendo a articulação entre teoria e realidade empírica.

Nesse contexto, destacamos que, em nossa pesquisa, o trabalho de campo consistiu na realização de entrevistas semiestruturadas com formadores(as) e coordenadores(as) dos cursos de especialização ofertados na Universidade Federal Rural de Pernambuco (UFRPE), pela matriz 2014, via Rede Nacional de Formação dos Profissionais da Educação Básica (RENAFORM). Os sujeitos entrevistados estavam com seus projetos oficialmente cadastrados no Ministério da Educação (MEC).

Dentre as temáticas ofertadas nos cursos de especialização, restringimo-nos: à Educação de Jovens e Adultos na diversidade - EJAD; à Educação do Campo - EC; à Política de Igualdade Racial no Ambiente Escolar - UNIAFRO e à Cultura e História dos Povos Indígenas - CHPI. Essas temáticas chamaram atenção por serem assuntos que a razão indolente (SANTOS, 2009) destrói, oculta e marginaliza. São temas que enfrentam a colonialidade do 
saber, do poder e do ser ao afirmar as relações de opressão sofridas por diversas populações e ao evidenciar a pluralidade de saberes e seres.

A partir do exposto, sistematizamos a seguir os achados de nossa pesquisa, a partir da análise temática proposta por Minayo (2010).

\section{A análise dos dados}

Para situar as falas dos nossos entrevistados e fazer a análise dos dados encontrados, é importante iniciar com uma breve caracterização desses sujeitos. Entrevistamos quatro formadores do curso de especialização em Cultura e História dos Povos Indígenas (ESP CHPI); dois formadores da especialização em Política de Igualdade Racial no Ambiente Escolar - UNIAFRO (ESP - UNIAFRO); um formador do curso de Educação do Campo (ESP - EC); e dois formadores da especialização Educação de Jovens e Adultos na diversidade (ESP EJAD). Entrevistamos, também, os coordenadores de cada um dos quatro cursos.

O perfil dos nossos entrevistados é de maioria do sexo feminino. Dos quatro coordenadores entrevistados, três são do sexo feminino e um do masculino; e dos nove docentes universitários, cinco são mulheres e quatro são homens. A faixa etária dos entrevistados foi: uma pessoa entre 20 e 30 anos, cinco entre 30 e 40 anos, três entre 40 e 50 anos e quatro entre 50 e 60 anos.

Com relação ao tempo de docência na educação superior, constatamos que o professor universitário com mais tempo de docência possui 15 anos na área. Os docentes formadores entrevistados tinham de 3 a 9 anos de docência universitária. Podemos, inclusive, afirmar que se apresenta como relevante esse período mínimo de experiência na prática para ministrar formação voltada para professores da educação básica.

Os docentes que participaram das entrevistas tinham formações ligadas à área das ciências humanas e educação, tanto na formação inicial quanto na pós-graduação. A maioria possuía doutorado em educação. Desse modo, observamos que os cursos em que eles atuam estão relacionados à sua área de formação.

\subsection{A relação entre a política de formação continuada e a reflexão sobre a profissionalidade docente universitária}

No contexto da execução e planejamento dos cursos de formação continuada analisados, observamos que os docentes universitários ressaltam a importância da contextualização da sua prática, na temática prevista nos cursos e com as turmas, que são professores da educação básica 
de diversos municípios pernambucanos. O docente universitário precisa lidar com profissionais que já têm experiência e saberes prévios, tanto a nível pessoal, quanto profissional, principalmente atuando na docência. Nas falas abaixo, os formadores nos mostram como essa experiência influencia na reflexão da sua docência:

Eu acredito, tal como Paulo Freire nos ensina, [que] não existe docência sem discência e vice-versa, é uma relação dialética; então, quando a gente se posiciona como docente para um curso de formação para docentes, a gente fortalece ess a relação dialética de aprendizagem conjunta. (Formadora 3 - ESP - UNIAFRO).

Para mim, é fantástico, porque são situações vivenciadas de histórias vividas que eu não consigo viver na universidade, que eu acabo aprendendo muito mais do que eu levo na sala de aula, eu acabo percebendo essas experiências e incorporando nas minhas disciplinas, cria um olhar crítico, e acaba existindo um olhar real, do que é a situação real para fora da universidade. (Formadora 6 - ESP - EJAD).

Com essas falas dos formadores, observamos que a aprendizagem também se faz para o docente do curso e não só para os cursistas, havendo assim um intercâmbio de saberes. Interessante destacar a sensação da Formadora 6 de que o real está fora da universidade. A ciência colonial, o saber hegemônico nas universidades, demonstra a sua colonialidade ao parecer fictícia. O esforço dos docentes universitários nesses espaços formativos é de trazer saberes e práticas pedagógicas que estejam em estreita relação com a prática do professor da educação básica.

A partir das falas, observamos que as políticas de formação continuada tendem a ser mobilizadoras de reflexões para os docentes universitários, além de agente desafiador no que se refere à sua atuação profissional a partir das demandas de formação instituídas em cada curso. Além disso, destacamos que a formação tende a assumir um papel importante para o desenvolvimento profissional dos docentes, renovando saberes e práticas. Nesse contexto, após o planejamento e antes do início do curso, observamos que os docentes perguntam: Que elementos são necessários para a atuação do docente universitário numa formação continuada? Sobre essa pergunta, identificamos que os formadores destacam a importância da reflexão sobre a prática, da valorização das experiências, do diálogo, do intercâmbio de saberes como sendo elementos importantes para a atuação da docência universitária nesse contexto. Esses questionamentos são profundamente decoloniais, pois colocam em xeque a suposta superioridade do saber acadêmico. Exige do saber universitário se colocar em relação, em diálogo com outros saberes. Decoloniza ao valorizar a prática, o concreto, a vivência. O saber colonial despreza o corpo e os saberes incorporados, colocando a teoria como algo superior à prática. Assim, formar professores do ensino básico demanda ao docente universitário rever suas certezas, que muitas vezes estão embasadas em uma lógica colonial. Observamos essa realidade nas seguintes falas: 
$\mathrm{Eu}$ acho que um elemento importante é o professor universitário estar aberto à realidade dos professores do ponto de vista do chão da escola [...] eu tenho que ter muita sensibilidade para perceber que muitos des ses profes sores que estão vindo hoje discutir a questão da história dos índios, eles foram formados em um período em que essas questões não eram debatidas. (Formador 1 - ESP - CHPI).

$\mathrm{Eu}$ acho que é muito importante a tal da vivência. Porque as pessoas reclamam muito. Entre a teoria e a prática ainda tem uma lacuna muito grande, então às vezes é muito cômodo a gente estar na academia teorizando, lendo, falando bonito, mas quando na prática há uma diversidade de empecilhos de dificuldades, não só do ponto de vista da motivação financeira, mas também estrutural, de condições, e por mais que às vezes a gente fale de determinadas metodologias, de determinadas teorias, às vezes a gente ainda fica muito longe para aqui dentro da academia e não tem essa vivência lá (Formadora 4 - ESP - EC).

Foi possível, também, trazer falas de formadores remetendo a uma crítica sobre o distanciamento da educação superior e a educação básica, e uma hierarquização ainda existente entre essas duas instâncias do ensino. Essa reflexão por parte dessas falas nos remete à importância da (re)configuração dessa profissionalidade docente, para que olhares mais atentos possam servir como uma quebra dessa hierarquização entre educação superior e educação básica. E que sirva mais como uma ponte entre essas duas modalidades de ensino e instituições.

E lembrando que, se você é um formador, e você está engajado na formação continuada, a sua formação também tem que ser nesse sentido, você não pode cobrar de profissionais da educação básica que estejam se formando continuadamente se você também para ali no tempo. Então é preciso que nós também estejamos nessa formação, nessa autoformação constante, o que cursos como esses ajudam muito. (Formador 2 - ESP - UNIAFRO).

O docente universitário, ao ser coordenador ou formador em uma formação continuada, está comprometido em atender às demandas da Política Nacional de Formação Inicial e Continuada de Profissionais da Educação Básica, instituída pela Portaria MEC n. 1.087, de 10 de agosto de 2011. Nessa dinâmica, a partir das demandas de formação expressas em catálogos de cursos, ocorria o planejamento da formação por uma equipe que pensava a dinâmica pedagógica e administrativa do curso.

Esse planejamento influencia a formação do docente universitário. Planejar as aulas dos cursos constitui-se no aprofundamento de estudos voltados para os temas propostos. A partir desse processo, observamos a indução de sistemáticas de estudo e pesquisa para a preparação das práticas de formação, o que nos leva a apontar que a política de formação e as temáticas do curso tendem a influenciar a reflexão da docência universitária, tanto para docentes que já tinham acúmulo de vivências na temática, quanto aos que contemplaram uma novidade para investigar, como nas falas a seguir: 
Teve uma cois a séria no curso de História e Educação indígena, que veio também uma temática chamada direitos humanos, que é um tema que eu venho me dedicado nos últimos tempos, e eu tive que, de uma certa forma, desafiar a ideia tradicional de direitos humanos, até porque não estou falando de direitos humanos liberal, estou falando do direito dos Povos Indígenas, que muitas vezes não é contemplado nessa lógica liberal dos direitos humanos [...] (Formador 1 - ESP - CHPI).

Primeiro porque eu já tinha sido professora da EJA, de uma modalidade dela, o Projovem Campo, então eu não tava falando de um público de aluno que eu não conhecia, porque eram alunos que estavam fora de faixa, então, para mim, era uma realidade que, na medida do possível, eu já conhecia, então pens ar metodologicamente os conteúdos, a forma de trabalhar desse professor, foi importante para mim porque eu já tinha vivência e facilitou esse processo de ensino e aprendizado, e compreender o lugar que eles estão, as necessidades que neles estão, porque no momento em que eu estava também foi minha necessidade, em um momento da minha vida foi minh a necessidade (Formadora 6 - ESP - EJAD).

A partir do exposto, podemos perceber a influência das políticas de formação continuada para a configuração da profissionalidade docente em diversas dimensões. Assim, podemos concordar com Morgado (2005), ao afirmar que a profissionalidade é construída, considerando a influência de múltiplos fatores. Sem dúvida, as exigências e desafios direcionados aos docentes universitários são inúmeros, principalmente num contexto que, segundo Zabalza (2004), demanda dos docentes conhecimentos específicos para exercer a docência adequadamente. E, nesse contexto, torna-se indispensável à aquisição dos conhecimentos e das habilidades vinculados à atividade docente para melhorar a sua atuação. Observamos abaixo a fala do formador que ressalta a importância dos saberes e sensibilidade para a atuação da docência nos cursos de formação continuada:

Então, aconteciam situações como uma dinâmica que você pensava, os estudantes diziam que ela não tinha como ser realizada, ela tinha muitos problemas, e assim por diante, ou seja, a experiência de ser professor de certa forma na especialização me colocou mais ainda numa posição de aluno, penso eu, de me enxergar como profess or e assim ir aperfeiçoando também a minha prática pedagógica nesse sentido (Formador 2 - ESP - UNIAFRO).

Ressaltamos, ainda, que foi notável nas falas dos formadores a presença de lacunas das formações iniciais, que em algumas vezes dificultam o trabalho desenvolvido em sala. Dentre elas, foram citadas algumas de cunho teórico e metodológico, conforme falas a seguir, o que nos chama atenção para o que anteriormente falamos sobre a função compensatória (GATTI, 2008) das formações continuadas:

As dificuldades tá no ponto de vista das limitações teóricas na forma que os professores da educação básica às vezes veem, no caso especificamente da pós graduação, que é uma pós-graduação dos professores, tendo em vista que eles não tinham experiência de, por exemplo, construir um artigo científico, uma resenha, resumo, cois as que a gente precisa. (Formador 1 - ESP - CHPI). 
Você pensa "são professores", mas são professores que têm dificuldade de ler, de escrever, não têm o hábito da leitura. Assim, são coisas que a gente entende que, por ser professor, não vá ter esse problema, mas na verdade a gente tem que trabalhar todas es sas questões. Pens ar na metodologia do trabalho que você vai levar para a sala de aula (Formadora 6 - ESP - EJAD).

A partir do exposto, podemos perceber a importância do planejamento da educação superior, especialmente em cursos de formação continuada para a construção de saberes contextualizados que consideram elementos da política educacional, e que ampliem os conhecimentos adquiridos na formação inicial.

\subsection{Situando limites e possibilidades para a política}

Analisar os limites e possibilidades da política de formação continuada nos leva a uma discussão em um nível experiencial das vivências relatadas pelos docentes universitários nas falas citadas, que nos remetem a pensar tanto o ensino como a investigação na universidade. Dentre os limites para a vivência da política de formação continuada, os sujeitos destacam: dificuldades entre temática e a realidade do cotidiano no qual os professores cursistas devem exercer suas atividades; os desafios de pensarmos um ensino reflexivo; a desarticulação entre formação inicial e continuada; e as dificuldades decorrentes da não continuidade dos estudos por parte dos professores. Encontramos relatos de dificuldades no depoimento abaixo:

A ideia da formação continuada, ela é sempre muito difícil de se concretizar na prática, porque ela sofre ingerência nos mais diversos contextos, ela acaba sendo muito fracionada, e aí a dificuldade de a gente construir mesmo ações, digamos assim, a longo prazo. (Formador 2 - ESP - UNIAFRO).

No caráter administrativo, também obtivemos alguns relatos de desafios, passando nessa instância da formação, no pensar em dar conta de burocracias, em suporte de secretariado:

$\mathrm{Eu}$ acho que a gente precisa de mais suporte na parte administrativa, eu queria levar mais tempo na sala de aula, acompanhando os trabalhos dos professores e dos cursistas, me vi envolvida com as questões de ordem administrativa burocrática (Coordenadora 1 - ESP - EC).

Desafios também por parte do uso da infraestrutura e da inclusão digital foram detectados em falas de entrevistas, e, ao mesmo tempo, formas que possibilitassem, ainda em meio a dificuldades, um breve acesso:

Até porque os nossos professores vêm de escolas do campo, muitas dessas escolas estão situadas em engenhos, em sítios muito distante da zona urbana, e não têm um sinal onde operadoras não investiram. [...] Muitos profes sores ainda não tinham muita familiaridade com o uso do computador, quando muito nas escolas que tinham lá o sinal, eles até utilizavam em alguns momentos muitas vezes eles iam para as lan houses. (Coordenadora 1 - ESP - EC) 
Para além desses limites, pensar políticas públicas de formação continuada no contexto da reflexão da prática docente universitária trouxe o pensar em possibilidades, como, por exemplo, repensar a própria dinâmica dos cursos universitários, a partir de uma lógica decolonial. Os movimentos sociais e as populações do campo demandam uma pedagogia da alternância, no sentido de garantir o tempo trabalho. Como esses sujeitos podem estar na universidade? É preciso que a universidade aprenda com essas experiências e se decolonize, no sentido de repensar, inclusive, a forma de organização do tempo.

Não só trabalhar o conhecimento só no tempo escola, mas também se considera o tempo comunidade como espaço educativo, e aí toda a universidade também deveria se estruturar para considerar is so, além de levar em consideração que é uma proposta política demandada pelos movimentos sociais, para agricultura familiar camponesa, para a agroecologia, para que tenha esses princípios, então tem toda uma proposta política ideológica muito diferente do que a estrutura da universidade vem fazendo historicamente. (Formadora 4 - ESP - EC)

Essa experiência também auxilia nos processos de decolonização de um aspecto fundamental na educação, que são os aspectos avaliativos. Nos cursos de formação, os aspectos dialógicos e circulares da avaliação são ressaltados e vivenciados de uma forma mais plena e livre de algumas amarras que a universidade impõe.

A coordenação, a supervisão, os professores, nós tínhamos com eles reuniões periódicas, pra que no grupo e coletivamente eles apontas sem como é que estava o desenvolvimento do curso, quais eram os entraves, quais eram as possibilidades que eles estavam encontrando, onde eles estavam avançando, ou quais eram os impedimentos ali para os avanços, então isso a gente fazia muito, nos encontros coletivos, atendíamos muito individualmente e garantíamos is so nas avaliações que eles fechavam nos componentes curriculares. [...] foram muitas as estratégias de avaliação, a gente se preocupou muito mais com a avaliação processual, com a avaliação muito mais qualitativa (Coordenadora 1 - ESP - EC).

Nas falas dos docentes, aparecem também novos temas, existe uma verdadeira sociologia das ausências (SANTOS, 2009) nas práticas formativas que visibilizam questões que o pensamento colonial acadêmico ignora. Um exemplo dessa riqueza temática é a seguinte fala:

E aproveitei as monografias para a gente discutir questões relacionadas à criança indígena, então, assim, o que era um problema, esse curso está nos apontando possibilidades de estar discutindo questões que muitas vezes não são visibilizadas, que é a his tória das crianças indígenas, de que crianças a gente está falando? Que elas são crianças indígenas ou indígenas crianças? Is so tudo está sendo problematizado. (Formador 1 - ESP - CHPI)

A partir do exposto, percebemos a existência de desafios e possibilidades que se constituem em elementos importantes para avanços na política de formação. Refletir sobre eles nos mobiliza a vivenciar o presente e planejar o futuro, visando a melhorias nas atividades de formação vivenciadas na universidade. Ressaltamos que a experiência traz elementos potentes 
para pensar a descolonização da prática docente universitária, o que contribui com a defesa da universidade pública, estatal, gratuita e de qualidade.

\section{Considerações finais}

A partir do exposto, concluímos que a política de formação continuada, viabilizada pelo RENAFORM, apesar dos desafios de sua implementação, apresenta-nos possibilidades de atuação e de descolonização das práticas de ensino. Sem dúvida, a reflexão acerca da docência universitária, nesse contexto, transcende a sala de aula, fazendo-nos refletir sobre o papel do ensino, pesquisa, extensão e gestão. E observar essas dimensões a partir de influências de uma política pública é desafiador, por se tratar de uma realidade na qual o docente universitário precisa planejar, coordenar, ministrar e avaliar os cursos.

Foi possível observar a importância do trabalho docente universitário nessas práticas formativas como uma maneira mais direta de interagir com as suas especialidades e a sua docência, com o contato direto com as demandas do chão da escola por meio dos professores da educação básica. Esse contato, segundo os diversos relatos encontrados, desafia os(as) docentes universitários(as) a pensar e repensar a sua prática docente, seja com os professores do ensino básico, seja com os estudantes universitários.

Assim, reconhecemos a importância dessa política pública, que se propôs a ofertar cursos em instituições públicas de ensino superior, de forma gratuita, para professores de ensino básico e que, a partir da execução da política, possibilitou a amplitude de reflexões, motivação e novas práticas, tanto por parte dos docentes universitários quanto dos docentes da educação básica. No entanto, estamos cientes de que só a implementação de uma política não basta. São necessários esforços para a sua permanência, sendo importantes a organização e um bom incentivo financeiro para que os avanços propostos por essa política sejam efetivos.

Dessa forma, tanto as instituições formativas como as escolas assumem posição fundamental na instituição de práticas críticas, considerando as demandas de formação e atuação na educação básica, fortalecendo, assim, o diálogo entre a educação básica e a superior, e valorizando uma educação democrática, progressista e decolonial. 


\section{Referências}

BRASIL. Lei de Diretrizes e Bases. Lei n. 9.394/96, de 20 de dezembro de 1996.

BRASIL. Portaria N. 1.328, de 23 de setembro de 2011. Institui a Rede Nacional de Formação Continuada dos Profissionais do Magistério da Educação Básica Pública.

BRASIL. Portaria MEC n. 1.087, de 10 de agosto de 2011. Institui a Política Nacional de Formação Inicial e Continuada de Profissionais da Educação Básica.

COSTA, Sérgio. (Re)Encontrando-se nas redes? As ciências humanas e a nova geopolítica do conhecimento. In: ALMEIDA, J.; MIGLIEVICH-RIBEIRO, A. e GOMES, H. T. Crítica póscolonial - panorama de leituras contemporâneas. Rio de Janeiro: 7 Letras, 2013.

DESLANDES, S. F. A construção do projeto de pesquisa. In: MINAYO, M. C. de S. (org.). Pesquisa social: teoria, método e criatividade. $23^{\mathrm{a}}$. ed. Petrópolis: Vozes, 2008.

DUSSEL, Enrique. Filosofía de Liberación. México: Edicol, 1977.

FREIRE, Paulo. Pedagogia do Oprimido. 32a . ed. Rio de Janeiro: Paz e Terra, 2002.

FREIRE, Paulo. Pedagogia da Autonomia: Saberes necessários à prática educativa. São Paulo: Paz e Terra, 1996.

GATTI, B. A. Análise das políticas públicas para formação continuada no Brasil, na última década. Revista Brasileira de Educação. V. 13, n. 37, jan./abr, 2008.

GROSFOGUEL, Ramón. From Postcolonial Studies to Decolonial Studies: Decolonizing Postcolonial Studies: A Preface, Review, 29(2), 2006.

KONTOPOULOS, Kyriakos. The Logic of Social Structures. Cambridge: Cambridge University Press, 1993.

MIGNOLO, Walter. Local Histories/Global Designs: Essays on the Coloniality of Power, Subaltern Knowledges and Border Thinking. Princeton: Princeton University Press, 2000.

MINAYO, M. C. de S. (org.). Pesquisa social: teoria, método e criatividade. 29a. ed. Petrópolis: Vozes, 2010.

MORGADO, J. C. Currículo e Profissionalidade Docente. Porto: Porto Editora LDA, 2005.

QUIJANO, Anibal. Coloniality of power, Eurocentrism and Latin America. Neplanta: Views from South. 1 (3), pp. 533-580, 2002.

RAMOS, K. M. da C. Reconfigurar a profissionalidade docente universitária: um olhar sobre ações de atualização pedagógica-didática. Porto: U.Porto Editoral, 2010.

ROLDÃO, M. do C. N. Nuances: estudos sobre educação. Ano XI, v. 12, n. 13, jan./dez, 2005. 
SANTOS, Boaventura de Sousa. Por uma pedagogia do conflito. In: FREITAS, A. L. S. de; MORAES, S. C. de (orgs.). Contra o desperdício da experiência: a pedagogia do conflito revisitada. Porto Alegre: Rede Editora, 2009.

ZABALZA, M. A. O ensino universitário: seu cenário e seus protagonistas. Porto Alegre: Artmed, 2004.

WALLERSTEIN, Immanuel. The Modern World-System. New York: Academic Press, 1974.

WALSH, Catherine. Interculturalidad, estado, sociedade: luchas (de)coloniales de nuestra época. Quito-Equador: Universidade Andina Simón Bolívar/Ediciones Abya-Yala, 2009. 